\title{
Weight Reduction Design of In-Wheel type Motor For Power density Improvement
}

\author{
Seung-Hee Chai ${ }^{1}$, Byeong-Hwa Lee ${ }^{1}$, Jung-Pyo Hong ${ }^{1}$, Senior member, IEEE \\ ${ }^{I}$ Department of Automotive Engineering, Hanyang University, 17 Haengdang-dong, Seongdong-gu, Seoul 133-791, \\ Korea
}

\begin{abstract}
This paper deals with the weight reduction design of In-Wheel type motor for high power density. Accordingly, characteristic and weight of the motor caused by modifying reduction gear ratio are examined. Weight of motor is minimized by modulating the ratio of stack length and external diameter of stator. Then, In-Wheel motor geometry based on the prototype is optimized to get the determined parameters using response surface methodology (RSM) and Finite Element Method (FEM). Optimal design of core usage in rotor is conducted for minimizing weight of motor which has identical characteristic to the prototype. Characteristic analysis is conducted by using equivalent circuit analysis of PM type motor. Through the presented weight of In-Wheel type motor, total weight is reduced to $25 \%$, and power density is improved to $57 \%$ from the prototype motor.
\end{abstract}

Keywords: IPMSM, In-Wheel, Weight reduction, Gear ratio, Power density,

\section{Introduction}

An IPMSM(Interior Permanent Magnet Synchronous Motor) having high output is widely applied to industries at the appropriate range for high speed and mechanical stability[1]. During last decades, In-Wheel type motor has been investigated extensively. Because this InWheel type motor is installed in Wheel directly; power train components can be removed, and it has high system efficiency. So, it can provide a system of new concept platform applied in the Eco-friendly car. Also, the moment that car braked, it is possible to improve a mileage collecting braking energy from regenerative braking control.

In this paper, it deals with the weight reduction design of In-Wheel type motor for power density improvement. For weight reduction and high power density, motor size is decreased and reduction ratio is increased. So, the weight of motor according to change in reduction gear ratio are minimized.

Also, Optimum design proceeded for reducing of the volume of rotor core, and result of power

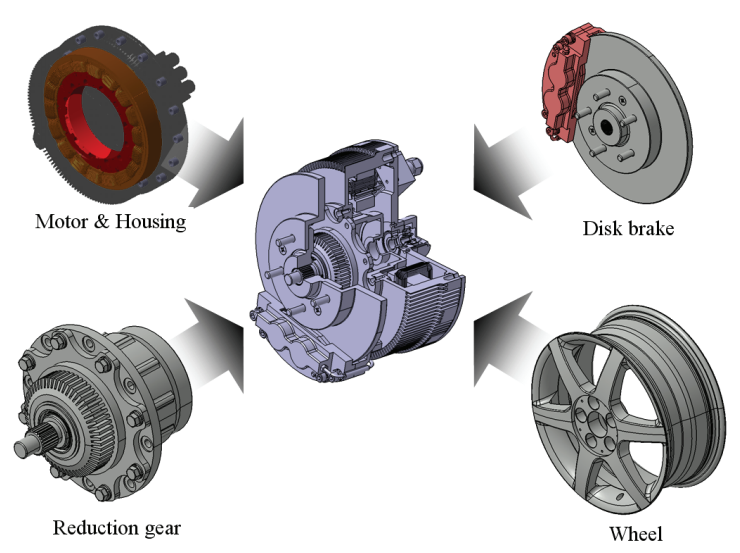

Figure 1.3D modeling of In-Wheel type motor 


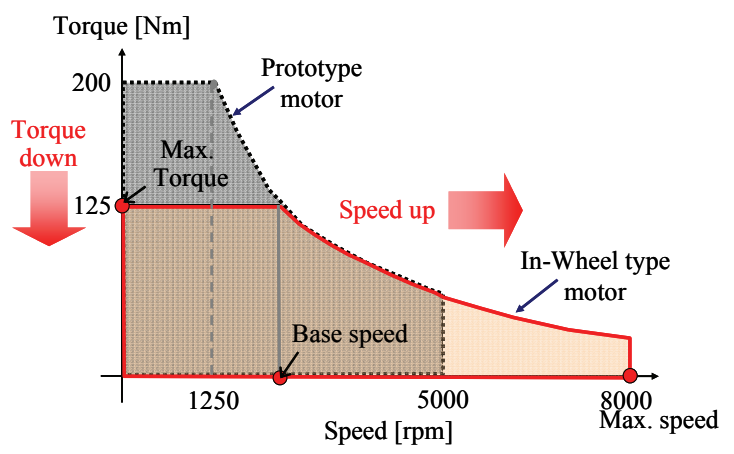

Figure 2. Characteristic of the motor according to change in reduction gear ratio

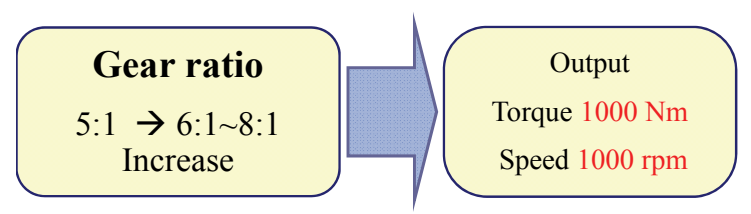

Figure 3. Object of target output

Table 1 : The output in Gear ratio

\begin{tabular}{|c|c|c|c|}
\hline Gear ratio & $6: 1$ & $7: 1$ & $8: 1$ \\
\hline Max. torque [Nm] & 167 & 143 & 125 \\
\hline Base speed [rpm] & 1400 & 1700 & 1900 \\
\hline Max. speed [rpm] & 6000 & 7000 & 8000 \\
\hline
\end{tabular}

Table 2 : Specifications of Motor

\begin{tabular}{|c|c|c|c|}
\hline & unit & $\begin{array}{c}\text { Prototype } \\
\text { motor }\end{array}$ & $\begin{array}{c}\text { Improved } \\
\text { motor }\end{array}$ \\
\hline Pole / slot number & - & $12 / 18$ & $12 / 18$ \\
\hline DC link Voltage & $\mathrm{V}_{\mathrm{DC}}$ & 320 & 320 \\
\hline Max./Rated Power & $\mathrm{kW}$ & $25 / 10$ & $25 / 10$ \\
\hline Max./Base Speed & $\mathrm{rpm}$ & $5000 / 1250$ & $8000 / 1900$ \\
\hline Stator outer dia. & $\mathrm{mm}$ & 300 & 270 \\
\hline Rotor outer dia. & $\mathrm{mm}$ & 221 & 201 \\
\hline Stack length & $\mathrm{mm}$ & 50 & 35 \\
\hline Cooling system & - & Air-cooling & Air-cooling \\
\hline winding & - & $\mathrm{Y}$ & $\mathrm{Y}$ \\
\hline Max. torque & $\mathrm{Nm}$ & 200 & 125 \\
\hline
\end{tabular}

density is compared with one in prototype. Characteristic analysis is conducted by using equivalent circuit analysis of PM type motor.

\section{Examination of Motor size as Changing Gear ratio}

Figure 2. is characteristic of the motor according to change in reduction gear ratio. According to the figure, it is necessary to control high speed range, but maximum torque decreases. The maximum torque is related to rotor volume, as shown in (1);

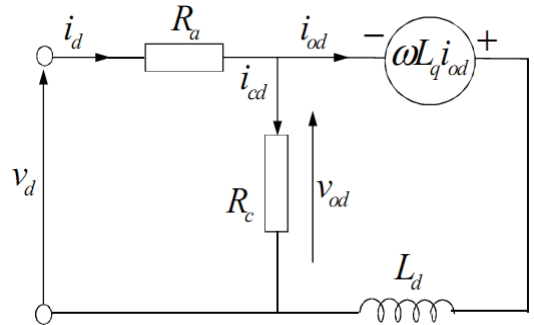

(a) d-axis equivalent circuits

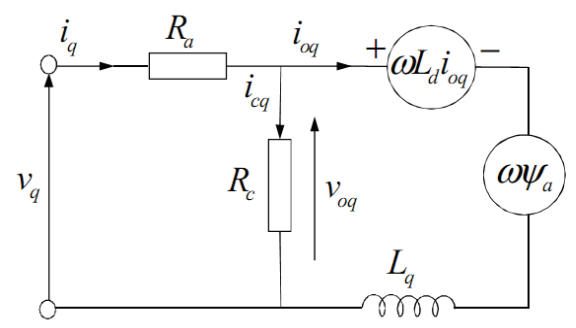

(b) q-axis equivalent circuits.

Figure 4. Equivalent circuits of IPMSM.

$$
T R V=\frac{T}{\frac{\pi}{4} D^{2} L_{s t k}}\left[k N m / m^{3}\right]
$$

where $T$ is torque, $D$ is a diameter of rotor, and $L_{\text {stk }}$ is stack length of rotor.

Thus, as gear ratio is increased, rotor volume of the motor is reduced. Simultaneously, it means motor weight is reduced.

\subsection{Change of the Gear ratio}

Increasing gear ratio is necessary to reduce the size. Figure 3. presents the object of target output. Maximum toque is $1000 \mathrm{Nm}$ and $1000 \mathrm{rpm}$ is object of maximum output speed. The feasible gear ratio is $6: 1 \sim 8: 1$, as shown in Table 1 . While gear ratio of former model is $5: 1$, satisfactory output power is examined by changing from $6: 1$ to $8: 1$. Also Maximum torque of former model is $195 \mathrm{Nm}$, those of improved model is examined by changing from $167 \mathrm{Nm}$ to $125 \mathrm{Nm}$.

\subsection{Selection of the Gear ratio}

Equation (2) decide maximum torque, maximum speed and output power depending on gear ratio.

$$
P=\omega T[W]
$$

Where, $P$ is output power $[\mathrm{kW}], \omega$ is speed of rotor $[\mathrm{rad} / \mathrm{s}]$, and $T$ is torque [Nm].

Gear ratio is determined $8: 1$ by the equation (1) and Table1. In this case, it provides fulfilling output power and reduce size of the rotor 


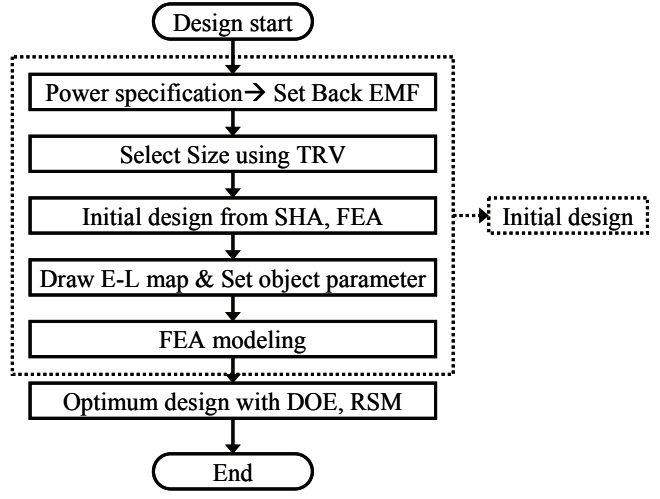

Figure 5. Process of motor design

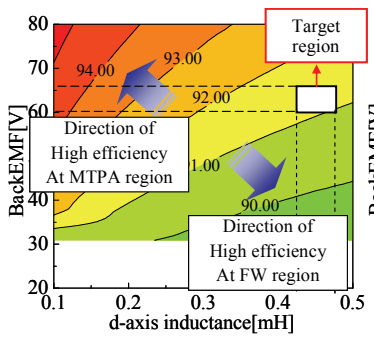

(a) Efficiency

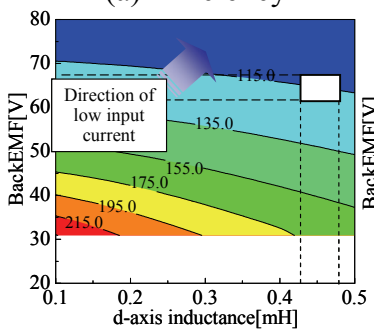

(c) Current

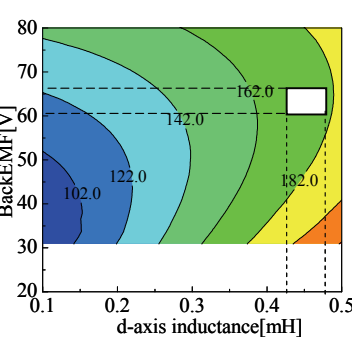

(b) Voltage

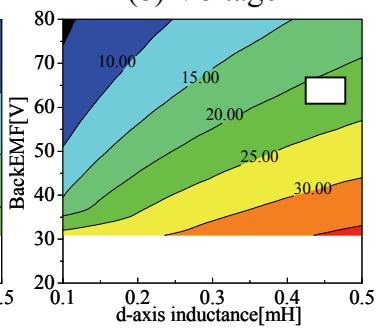

(d) Current angle
Figure 6. E-L map (@25kW, 1900rpm)

considerably according to equation (1). Table2 shows reduced size of the rotor adequately.

\section{Motor Design and Characteristic analysis}

Table 2 shows specifications of prototype motor and improved In-Wheel type motor. Rotor, stator diameter and stack length are reduced. The number of poles and slots, and voltage specification are equal to prototype motor's.

\subsection{Initial Design of In-Wheel Motor}

Figure 5. shows design process of the In-Wheel motor used in this paper[2]. E-L map at maximum rating and base rpm is shown in Figure 6. Using E-L map, goal parameters of motor can be determined goal parameters of motor can be determined in less time with changing the back-
EMF and inductance value as major parameters of motor. Equation(3)-(5) are voltage equation using d-q axis equivalent circuit shown in Figure 6. By these equations, E-L map is fixed and characteristic of motor is evaluated.

$$
\begin{gathered}
{\left[\begin{array}{l}
v_{d} \\
v_{q}
\end{array}\right]=R_{a}\left[\begin{array}{l}
i_{o d} \\
i_{o q}
\end{array}\right]+\left(1+\frac{R_{a}}{R_{c}}\right)\left[\begin{array}{l}
v_{o d} \\
v_{o q}
\end{array}\right]+p\left[\begin{array}{cc}
L_{d} & 0 \\
0 & L_{q}
\end{array}\right]\left[\begin{array}{l}
i_{o d} \\
i_{o q}
\end{array}\right]} \\
{\left[\begin{array}{c}
v_{o d} \\
v_{o q}
\end{array}\right]=\left[\begin{array}{cc}
0 & -\omega L_{q} \\
\omega L_{d} & 0
\end{array}\right]\left[\begin{array}{l}
i_{o d} \\
i_{o q}
\end{array}\right]+\left[\begin{array}{l}
0 \\
\omega \psi_{a}
\end{array}\right]} \\
T=P_{n}\left\{\psi_{a} i_{o q}+\left(L_{d}-L_{q}\right) i_{o d} i_{o q}\right\}
\end{gathered}
$$

Where $i_{d}$ and $i_{q}$ are d- and q-axis component of armature current, $i_{c d}$ and $i_{c q}$ are d-and q-axis component of terminal voltage, $R_{a}$ is armature winding resistance per phase, $R_{c}$ is iron loss resistance, $\Psi_{a}$ is flux linkage of permanent magnet per phase (rms value), $L_{d}$ and $L_{q}$ are d-and q-axis armature self-inductance, and $P_{n}$ is pole pair [5].

\subsection{Optimum Design \& Characteristic Analysis}

Finally, optimization step with DOE and RSM is progressed to improve motor characteristics [3]. Final optimization model parameters calculated using the finite element method and then analyzed characteristics using equivalent circuit [4], [5]. It is accomplished the reduction of the motor's weight by minimizing the usage of core inside a rotor. The areas, which are not related to magnetic paths, are cut through optimal design technique. Figure 7. indicates the regions for optimization and the lower amount of irons used while the properties that the motor has are being preserved. Consequently, $20 \%$ of the total quantity of the materials consumed is declined. At the same time, we manufacture the model considering the safety coefficient 2 based on structural and stiffness analysis about the rotor. Figure 8 indicates the results through structural analysis at the maximum speed 8000rpm. And two motors compared to the weight and power density.

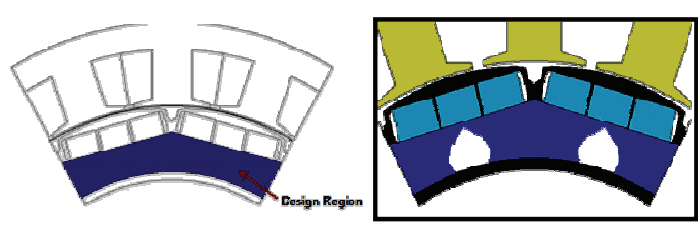

Figure 7. Optimum design of rotor 


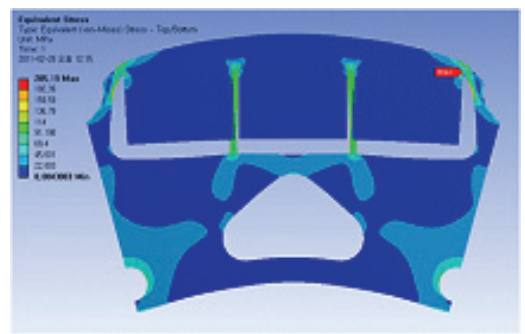

Figure 8. Structure analysis of rotor

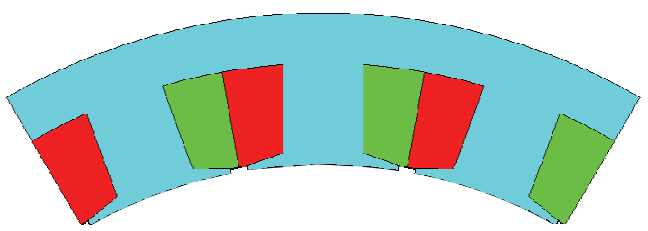

(a) Stator

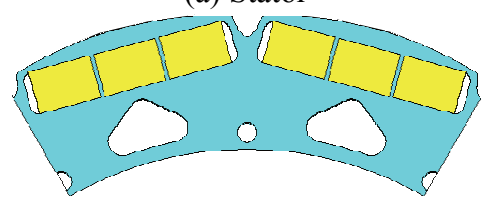

(b) Rotor

Figure 9. Structures of In-Wheel type motor

Table 3 : Weight and power density

\begin{tabular}{|c|c|c|c|}
\hline Contents & unit & $\begin{array}{c}\text { Prototype } \\
\text { motor }\end{array}$ & $\begin{array}{c}\text { Improved } \\
\text { motor }\end{array}$ \\
\hline $\begin{array}{c}\text { Weight1 } \\
\text { (Rotor \& Stator) }\end{array}$ & $\mathrm{kg}$ & 16.6 & 7.9 \\
\hline $\begin{array}{c}\text { Weight2 } \\
\text { (Housing \& Gear) }\end{array}$ & $\mathrm{kg}$ & 16.4 & 13.0 \\
\hline $\begin{array}{c}\text { Power density } \\
\text { (Weight 1) }\end{array}$ & $\mathrm{kW} / \mathrm{kg}$ & 1.51 & 3.16 \\
\hline $\begin{array}{c}\text { Power density } \\
\text { (Weight 1+2) }\end{array}$ & $\mathrm{kW} / \mathrm{kg}$ & 0.76 & 1.20 \\
\hline
\end{tabular}

\section{Results \& Experiments}

The feature of improved In-Wheel type motor is shown in figure 9. Results comparing the power of the prototype and the improved model are shown in Figure 10. And results comparing the weight of the prototype and the improved model are shown in Table. 3.

\subsection{Reduction of the size $\&$ the weight}

It shows that the novel model weight $52 \%$ less than prototype as motor single item. This weight is calculated though considering the density of coil and permanent magnet. Although the weight of motor was reduced, but it increases the gear ratio, so the gear changed from one planetary gear to two planetary gears. The weight of gear also changed from $5.6 \mathrm{~kg}$ to $8.7 \mathrm{~kg}$. Thus, in the end, the weight of improved motor reduced $25 \%$ than prototype. Similarly, the output power has same level in each operating region at $25 \mathrm{~kW}$.

\subsection{Power density}

As shown in Table 3, power density of prototype motor is $0.76 \mathrm{~kW} / \mathrm{kg}$ while that of improved motor is $1.2 \mathrm{~kW} / \mathrm{kg}$. It is increasing about $57 \%$. So, this is obviously acceptable to explain high power density.

\subsection{Experiments}

Designed in-wheel motor is fabricated. Maximum power is $25 \mathrm{~kW}$ respectively, as shown in Figure 10. The in-wheel motor obtained by FEA and test a load condition is compared in Fig. 11 which is compared with voltage, input current and efficiency according to speed at max., rated power. And Fig. 12 and Fig. 13 are test setup for load test and fabricated in-wheel motor system.[6]

\section{Conclusion}

In this paper, the weight of the motor was reduced to increase the gear ratio. In this case, the gear ratio is determined by considering size and weight of the reduction gear as well as weight of the motor. In addition, the Initial shape is determined by design process, and decreased $20 \%$ in the areas of design by remove the useless core from the rotor. Consequently, the motor was designed to meet the target attribute. And the weight of the motor was approximately $25 \%$ reduction. Also, In order to improve the power density, the output power of the motor at constant power region is preserved. And to conclude, motor's power density is improved to $57 \%$ from prototype motor, as shown in this paper. Finally, designing In-Wheel motor, and designed motor is verified by experiments.

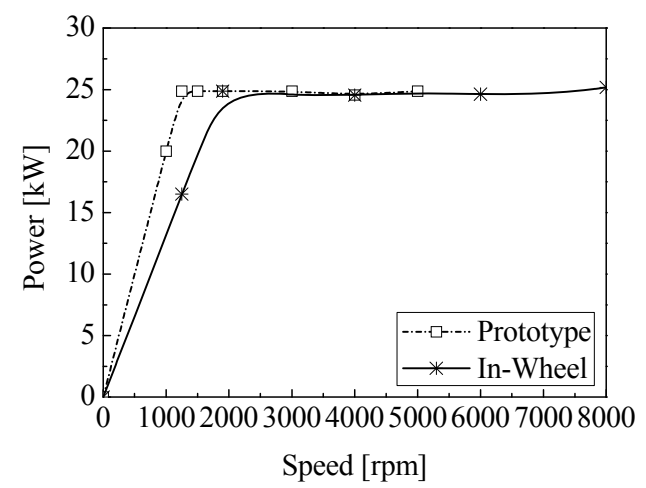

Figure 10. Output of two type of motor 


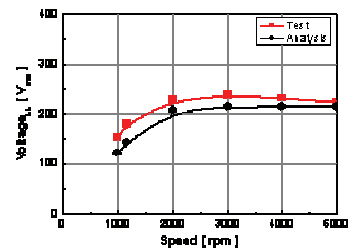

(a) Voltage

@ rated output power

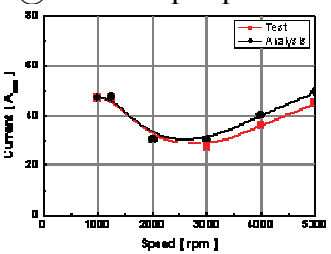

(c) Current

@ rated output power

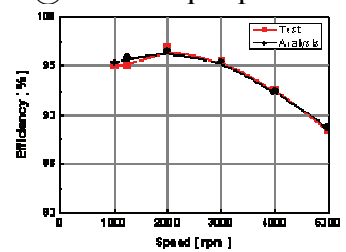

(e) Efficiency

(a) rated output power

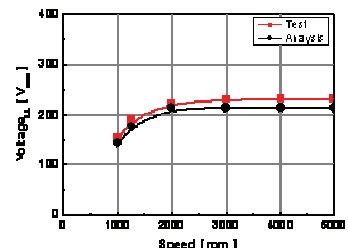

(b) Voltage

(a) max. output power

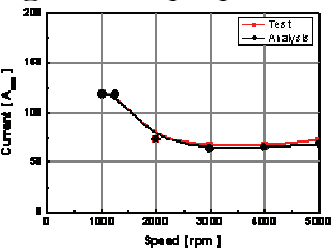

(d) Current

@ max. output power

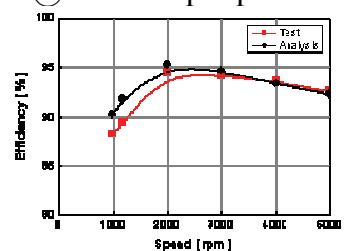

(f) Efficiency

(a) max. output power

Fig. 11. Comparison of test and analysis results

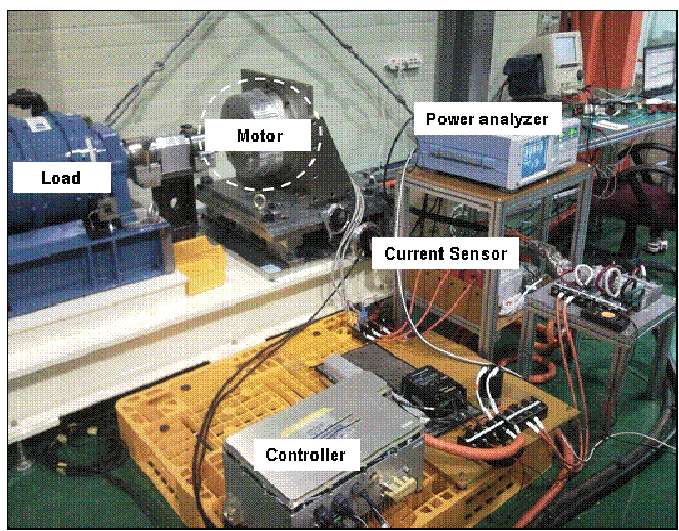

Fig. 12. Test setup for load test

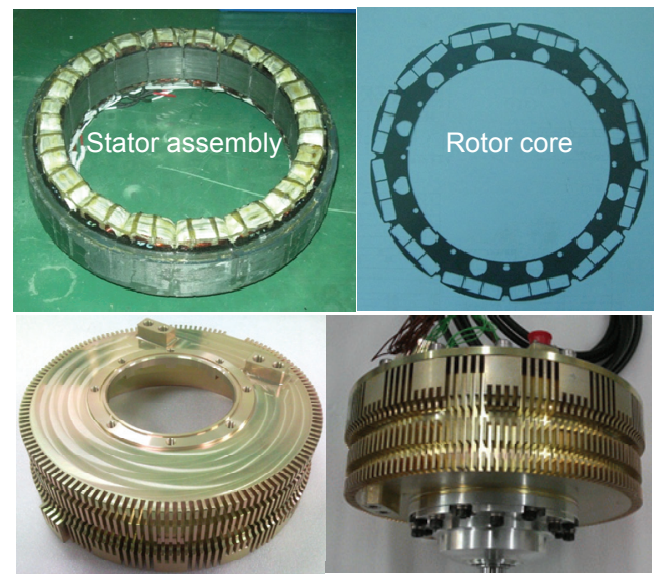

Fig. 13. Fabricated rotor and stator and motor

\section{References}

[1] M. Ehsani, Y. Gao, S. E. Gay, and A. Emadi, "Modern electric, hybrid electric, and fuel cell vehicles", CRS Press, 2005

[2] Soon-O Kwon, Sung-Il Kim, Suk-Hee Lee, Jung-Pyo Hong, "Design of BLDC motor using Parametric design", KIEE, pp. 10131014,2007

[3] Y. P. Yang and D. S. Chuang, "Fluxweakening Control of Permanent Magnet Synchronous Motor Using in Electric Vehicles", IEEE Tran. on Magn., vol. 43, no. 1, pp.51-61, Jan. 2007

[4] J. Y. Lee, S. H. Lee, G. H. Lee, J. P. Hong, J. Hur, "Determination of parameters considering Magnetic Nonlinearity in an Interior Permanent Magnet Synchronous Motor" IEEE Trans. Magn.,vol. 42, no 4, pp.1303-1306, April 2006

[5] Jae-Woo Jung, Jeong-Jong Lee, Soon-O Kwon, Jung-Pyo Hong, Senior Member, IEEE Ki-Nam Kim, "Equivalent Circuit Analysis of Interior Permanent Magnet Synchronous Motor Considering Magnetic saturation", EVS, May 2009.

[6] Byeong-Hwa Lee, Sung-Il Kim, Jeong-Jong Lee, Jung-Pyo Hong, Chang-Soo Park, "Design of an Interior Permanent Magnet Synchronous In-Wheel for Electric Vehicles", ICEMS, Oct 2010.

\section{Authors}

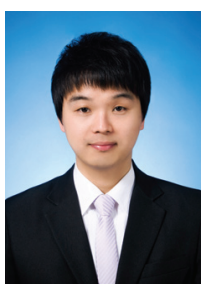

Seung-Hee Chai received degree in Mechanical engineering from the Hanyang University, Korea, in 2009. Currently he is pursuing the Ph.D. degree in automotive engineering from Hanyang University, Korea. His main fields of interests are optimization, analysis, design of electric machine for Vehicle tractoion and numerical analysis of electromagnetic.

Byeong-Hwa Lee received M.S. degree in Automotive engineering from the Hanyang University, Korea, in 2009. Currently he is pursuing the Ph.D. degree in automotive engineering from Hanyang University, Korea. Her main fields of interests are electromagnetic field analysis and electrical motor design related to the IPMSM for Vehicle traction. 
Jung-Pyo Hong received Ph.D. degree in electrical engineering from the Hanyang University, Korea, in 1995. From 1996 to 2006, he was professor of Changwon National Univ., Changwon, Korea. Since 2006 he has been working as a professor in the Hanyang University, Korea. His research interests are the design of electric machines, optimization and numerical analysis of electromechanics. 